\title{
Multi Objective Optimisation of Turning Process Parameters on EN 8 Steel using Grey Relational Analysis
}

\author{
G. Sridhar ${ }^{\mathrm{a}}, \mathrm{G}$. Venkateswarlu $\mathrm{u}^{\mathrm{a}, \mathrm{b}}$ * \\ ${ }^{a, b}$ Department of Mechanical Engineering, Sree Chaitanya College of Engineering, Karimnagar, India
}

\begin{abstract}
The objective of the present paper is to optimize the machining parameters for turning of EN8steel on lathe machine using a combination of Taguchi and Grey Relational Analysis to yield minimum cutting forces and surface roughness. The process parameters such as rotational speed, feed, depth of cut and cutting fluid have been selected. In this study, the experiments were carried out as per Taguchi experimental design and $\mathrm{L}_{9}$ orthogonal array was used. Analysis of variance (ANOVA) was also used to find out the most influence of processing parameters on the responses. The regression equations were also established between the process parameters and responses. The results indicate that the depth of cut is the most significant factor affecting the cutting force and surface roughness followed by a feed, speed and cutting fluid.
\end{abstract}

Index Terms: Turning, Taguchi method, Grey relational analysis, EN8 steel.

(C) 2014 Published by MECS Publisher. Selection and/or peer review under responsibility of the Research Association of Modern Education and Computer Science.

\section{Introduction}

Turning process is one of the most used machining process in which the material is removed from the outer surface of the work piece. This process produces various shapes of materials such as conical, curved, cylindrical, straight, etc. There are many turning process parameters such as cutting speed, feed, depth of cut, cutting fluid etc. influence the quality of the machining [1]. Therefore, the machining process parameters should be optimized to achieve high cutting performance. Cutting forces influence the deformation of work piece, dimensional accuracy, chip formation and machining system stability [2]. In machining process, surface roughness plays an important role as it influences the fatigue strength, wear resistance, corrosion resistance. Therefore, it is required to measure the cutting forces and surface roughness of the machined part. The material under investigation, EN 8 steel is used in many manufacturing parts such as shaft crank shafts, automobile axle beams, connecting rods, lightly stressed gears due to its high tensile strength. Many studies have been carried out on optimization of machining process parameters.

* Corresponding author. Tel.: 9032194173

E-mail address: ganta_hmp@ rediffmail.com 
Dil bag et al. [3] studied the effect of rake angle, cutting speed, feed rate and nose radius on surface finish and concluded that feed is the most influential factor on surface roughness. Bach et al. [4] investigated the influences of cutting speed, feed and depth of cut on cutting forces and surface roughness using the Taguchi te chnique during turning of AISI 52100 bearing steel with CBN tool. Results indicated that the depth of cut is a dominant factor affecting cutting forces and surface roughness followed by feed and depth of cut. Wang et al. [5] applied Taguchi and Grey relational technique to optimize turning process parameters to achieve minimum surface roughness and tool wear. Yahya [6] conducted an experimental investigation on effect of cutting fluids in turning of AISO1050 steel with coated carbide tool. They found that cutting fluid did not show significant improvement on surface roughness, but reduced tool wear and cutting forces. Yazdani et al. [7] proposed a new model to solve optimal substation planning in distribution networks. The optimization problem was solved by genetic algorithm (GA). Wang et al. [8] was used simulation annealing algorithm to optimize the parameters of support vector machine. Mahdavinejad et al. [9] optimized tuning parameters of AISI 304 stainless steel using Design of Experiment and also conducted an ANOVA test to determine the effect of each parameter on surface roughness and tool wear. Results showed that cutting speed has main influence on the flank wear and feed rate on surface roughness. Allattin et al. [10] presented a report on optimization finish turning of hardened AISI D6 cold work tool steel with ceramic and cubic boron nitride cutting tools using Grey relational analysis. They found that feed rate was the most significant controllable machining factor for finish hard turning of the material. Yinfong et al. [11] applied Grey relational analysis to optimize the process parameters in turning of tool steels. They selected eight independent variables such as cutting speed, feed, depth of cut, coating type, type of insert, chip breaker geometry, coolant and nose radius for the optimization.

Based on the above facts, multi optimization of turning process parameters was done using Grey relational analysis and also determined the influence of process parameters on the responses using ANOVA analysis. In the present work, statistical analysis software MINITAB 15 was used for the design of experiments, to perform ANOVA analysis and also to establish regression models.

\section{Methodology}

\section{1. Taguchi Method}

Taguchi technique is a power full statistical tool for analysing and optimizing the process parameter parameters. The Taguchi method uses orthogonal arrays from design of experiments, theory to study a large number of variables with a small number of experiments. The experimental results are then transformed into a signal-to-Noise $(\mathrm{S} / \mathrm{N})$ ratio. It uses the $\mathrm{S} / \mathrm{N}$ ratio as a measure of quality characteristics deviating from or nearing to the desired values [12]. Taguchi classified the quality characteristics into three categories such as Lower the better, Higher the better and Normal the better. The formula used for calculating $\mathrm{S} / \mathrm{N}$ ratio is as follows.

Smaller the better: $\mathrm{S} / \mathrm{N}$ ratio $(\eta)=-10 \log _{10} \frac{1}{n} \sum_{i=1}^{n} y_{i}^{2}$

Where $y_{i}=$ observed response value, $\mathrm{n}=$ number of replications.

Nominal the best: It is used where the nominal or target value and variation about that value is minimized.

$\mathrm{S} / \mathrm{N}$ ratio $(\eta)=-10 \log _{10} \frac{\mu^{2}}{\sigma^{2}}$

Where $\mu=$ mean and $\sigma=$ variance 
Higher the better: It is used where the larger value is desired.

S/N Ratio $(\eta)=-10 \log 10 \frac{1}{n} \sum_{i=1}^{n} \frac{1}{y_{i}^{2}}$

Where, $y_{i}=$ observed response value, $\mathrm{n}=$ number of replications.

\subsection{Selection of Process Parameters}

In this investigation, turning process parameters such as speed, feed, depth of cut and cutting fluid were considered. According to Taguchi's design of experiments, for four parameters and three levels $\mathrm{L}_{9}$ Taguchi orthogonal array [13] was selected. The number of factors and their corresponding levels are shown in the Table 1

Table1. Selected variable levels for turning

\begin{tabular}{ccccc}
\hline Code & Variable & Level 1 & Level 2 & Level 3 \\
\hline 1 & Spindle speed (s, rpm) & 490 & 600 & 790 \\
2 & Feed rate (f, mm / rev) & 0.022 & 0.066 & 0.108 \\
3 & Depth of cut (d, mm) & 0.5 & 0.75 & 1 \\
4 & Cutting fluid type (cf) & Palmolive oil & Soluble oil & Straight cutting oil \\
\hline
\end{tabular}

\subsection{Grey Relational Analysis}

Grey theory was proposed by Dr. Deng includes Grey relational analysis, Grey modelling, prediction and decision making of a system. This model estimates the behavior of unknown system [14] and also successfully applied to many applications includes industry, social systems, ecological systems, economy, geography, traffic, management, education, environment etc. [15-17]. The following steps are involved in multi objective optimization of process parameters using Grey relational analysis [14].

1. Conduction of experiments at different sets of parameters based on orthogonal array.

2. Normalization of raw data of experimental results for all performance characteristics.

3. Calculation of quality loss function.

4. Calculation of Grey relational coefficient.

5. Principal component analysis to optimize the corresponding weighting value for each performance characteristics.

6. Calculation of Grey relational grade using a weighting factor for performance characteristics during Grey relational generation, the normalized data corresponding to

Higher-the-Better (HB) criterion can be expressed as:

$$
x_{i}=\frac{\max y_{i}(k)-y_{i}(k)}{\max y_{i}(k)-\min y_{i}(k)}
$$


Lower-the-Better (LB) criterion can be expressed as:

$$
x_{i}=\frac{y_{i}(k)-\min y_{i}(k)}{\max y_{i}(k)-\min y_{i}(k)}
$$

Nominal-the-better type can be expressed as:

$$
x_{i}=\frac{y_{i}(k)-y_{0}}{\max y_{i}(k)-y_{0}}
$$

Where $x_{i}(k)$ is the value after the Grey relational generation, $\min y_{i}(k)$ and $\max y_{i}(k)$ are the smallest value and largest values of $y_{i}(k)$ for the $\mathrm{k}^{\text {th }}$ response. The definition of the Grey relational grade in the Grey relational analysis is to show the relational degree between the nine sequences $\left[\mathrm{x}_{0}(\mathrm{k})\right.$ and $\mathrm{x}_{\mathrm{i}}(\mathrm{k}), \mathrm{i}=1,2, \ldots \ldots, 9$;

$\mathrm{k}=1,2, \ldots, 9]$.

The measurement for quantification in Grey relational space is called the Grey relational grade. Before obtaining a Grey relational grade, Grey relational coefficient to be obtained.

The Grey relational coefficient $\xi_{\mathrm{i}}(\mathrm{k})$ can be calculated as

$$
\zeta_{i}(k)=\frac{\Delta_{\min }+\zeta \Delta_{\max }}{\Delta_{0 i}+\zeta \Delta_{\max }}
$$

Where $\Delta_{0 \mathrm{i}}=\left\|\mathrm{x}_{0}(\mathrm{k})-\mathrm{x}_{\mathrm{i}}(\mathrm{k})\right\|=$ difference of the absolute value between $\mathrm{x}_{0}(\mathrm{k})$ and $\mathrm{x}_{\mathrm{i}}(\mathrm{k}) ; \zeta=$ distinguishing coefficient $(0 \sim 1) ; \Delta_{\min }=\forall \mathrm{j}^{\min } \in \mathrm{i} \forall \mathrm{k}^{\min }\left\|\mathrm{x}_{0}(\mathrm{k})-\mathrm{x}_{\mathrm{j}}(\mathrm{k})\right\|=$ smallest value of $\Delta_{0 \mathrm{i}}$; and $\Delta_{\max }=\forall \mathrm{j}^{\max } \in \mathrm{i} \forall \mathrm{k}^{\max } \| \mathrm{x}_{0}(\mathrm{k})$ $\mathrm{x}_{\mathrm{j}}(\mathrm{k}) \|=$ largest value of $\Delta_{0 \mathrm{i}}$.

$$
\gamma_{i}=\frac{1}{n} \sum_{k=1}^{n} \zeta_{i}(k)
$$

Where $\mathrm{n}=$ number of responses

The next step is to assign weights or relative importance to the quality characteristics. A number of methods exist for the assessment of weights. The weights should be assigned such that the following condition holds:

$$
\sum_{i}^{n} W_{i}=1
$$

The average values of Grey relational grade are found out separately for each level and for each parameter. Then the optimal setting of process parameters is found out for optimum Grey relational grades. Then the mean responses and the main effects in terms of the Grey relational grade values are calculated. Then analysis of variance is performed to get the significant factors.

\subsection{Experimental Details}

EN 8 steel was used as the work material for this work and its chemical composition is given in the Table 2. The work piece material specimen size of $\emptyset 20 \times 100 \mathrm{~mm}$ was cut from a rod. The turning experiments were 
carried out according to $\mathrm{L}_{9}$ orthogonal array as shown in Table 3 on a lathe (TURN MASTER-350 made) machine with dynamometer attachment. The experimental setup used for turning operation is shown in Fig.1. Each experiment was carried out twice to minimize the experimental error. The cutting forces in $\mathrm{X}$ direction $(\mathrm{Fx}), \mathrm{Y}$ direction $(\mathrm{Fy}) \& \mathrm{Z}$ direction $(\mathrm{Fz})$ were measured using a dynamometer. The resultant cutting force $(\mathrm{F})$ was calculated using equation (10).

$$
F=\sqrt{F_{x}^{2}+F_{y}^{2}+F_{z}^{2}}
$$

After conducting experiments, the quality of machined work pieces was measured in terms of the surface roughness of the surface using a Surtronic $3+$ Taylor Hobson Talysurf surface profilo meter.

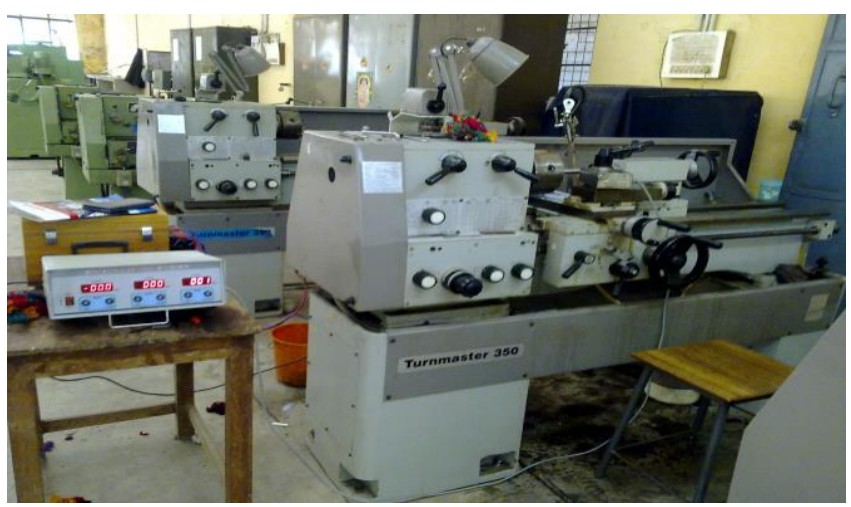

Fig.1. Experimental setup

Table 2. Chemical composition of en 8 steel

\begin{tabular}{cccccc}
\hline Element & $\mathrm{C}$ & $\mathrm{Si}$ & $\mathrm{Mn}$ & $\mathrm{S}$ & $\mathrm{P}$ \\
\hline$\% \mathrm{Wt}$ & 0.4 & 0.25 & 0.8 & 0.015 & 0.015 \\
\hline
\end{tabular}

Table 3. The basic Taguchi L9 (34) orthogonal array

\begin{tabular}{ccccc}
\hline Expt. No & \multicolumn{4}{c}{ Control factors and their levels } \\
& A & B & C & D \\
\hline 1 & 1 & 1 & 1 & 1 \\
2 & 1 & 2 & 2 & 2 \\
3 & 1 & 3 & 3 & 3 \\
4 & 2 & 1 & 2 & 3 \\
5 & 2 & 2 & 3 & 1 \\
6 & 2 & 3 & 1 & 2 \\
7 & 3 & 1 & 3 & 2 \\
8 & 3 & 2 & 1 & 3 \\
9 & 3 & 3 & 2 & 1 \\
\hline
\end{tabular}




\section{Results and discussion}

\subsection{Optimization of Process Parameters}

The following steps were followed to optimise the turning processing parameters using Gray relational analysis

(1) Normalize the data.

(2) Calculate the corresponding Grey relational coefficients.

(3) Calculate the Grey relational grade

(4) Perform statistical analysis of variance (ANOVA).

(5) Select the optimal levels of cutting parameters.

(6) Conduct confirmation experiments.

In the present study, the cutting force and surface roughness of each sample in different process parameters are listed in Table 4. In turning operation, lower the cutting force and surface roughness are the indication of higher performance. For normalizing the responses in the Grey relational analysis process, lower the better (LB) criterion has been chosen for both cutting force and surface roughness.

The data is normalised using equation (5) to obtain Grey relational generation. The normalised data and $\Delta_{0 \mathrm{i}}$ for each of the responses have been presented in Table 5 and Table 6 respectively.

Table 4. Taguchi's L9 standard orthogonal array with responses

\begin{tabular}{ccc}
\hline Sample No. & Cutting Force $(\mathrm{F})$ & Surface Roughness $(\mathrm{Ra})$ \\
\hline 1 & 27.50 & 2.42 \\
2 & 81.47 & 4.92 \\
3 & 165.00 & 9.50 \\
4 & 75.00 & 2.92 \\
5 & 123.34 & 7.35 \\
6 & 86.65 & 5.24 \\
7 & 95.00 & 8.10 \\
8 & 65.00 & 3.43 \\
9 & 126.00 & 6.80 \\
\hline
\end{tabular}

Table 5. Gray relational generation of each performance characteristics

\begin{tabular}{ccc}
\hline Specimen No. & Cutting Force & Surface Roughness \\
& & \\
\hline 1 & 0.000 & 0.000 \\
2 & 0.392 & 0.353 \\
3 & 1.000 & 1.000 \\
4 & 0.345 & 0.070 \\
5 & 0.697 & 0.696 \\
6 & 0.430 & 0.398 \\
7 & 0.490 & 0.802 \\
8 & 0.272 & 0.142 \\
9 & 0.716 & 0.618 \\
\hline
\end{tabular}


$\Delta_{0 \mathrm{i}}$ for each of the responses have been calculated as follows.

$\Delta_{01}(1)=\left(\mid \mathrm{x}_{0}(\mathrm{k})-\mathrm{x}_{\mathrm{i}}(\mathrm{k})\|=\| 1.0000-0.000 \|=1.000\right.$

$\Delta_{01}(2)=\left(\mid \mathrm{x}_{0}(\mathrm{k})-\mathrm{x}_{\mathrm{i}}(\mathrm{k})\|=\| 1.0000-0.000 \|=1.000\right.$

Therefore $\Delta_{01}=(1.000,1.000)$

The same calculating process was used for $\mathrm{i}=1-9$ and the results of all $\Delta_{0 \mathrm{i}}$ are presented in Table 6

$\Delta_{\max }(k)$ and $\Delta_{\min }(k)$ are taken as follows

$\Delta_{\max }=\Delta_{03}(1)=\Delta_{03}(2)=1.000$

$\Delta_{\min }=\Delta_{01}(1)=\Delta_{01}(2)=0.000$

Grey relational coefficients calculated by the equal weight (0.5) of each performance characteristic using equation (7) and presented in Table 7. The calculation of Grey relational coefficient is as follows.

$$
\begin{aligned}
& \xi_{01}(\mathbf{1})=\frac{0.0+0.5 \times 1.0}{1.0+0.5 \times 1.0}=0.333 \\
& \xi_{02}(\mathbf{1})=\frac{0.0+0.5 \times 1.0}{1.0+0.5 \times 1.0}=0.333
\end{aligned}
$$

A similar procedure is applied for $i=1-9$ for calculating Grey relation coefficients.

Table 6. Evaluation of $\Delta 0$ i for each of the responses

\begin{tabular}{ccc}
\hline Specimen No. & Cutting Force & Surface Roughness \\
\hline 1 & 1.000 & 1.000 \\
2 & 0.608 & 0.647 \\
3 & 0.000 & 0.000 \\
4 & 0.655 & 0.930 \\
5 & 0.303 & 0.304 \\
6 & 0.570 & 0.602 \\
7 & 0.510 & 0.198 \\
8 & 0.728 & 0.858 \\
9 & 0.284 & 0.382 \\
\hline
\end{tabular}

Table 7. Grey relational coefficient of each performance characteristics

\begin{tabular}{ccc}
\hline Specimen No. & Cutting Force & Surface Roughness \\
\hline 1 & 0.333 & 0.333 \\
2 & 0.451 & 0.435 \\
3 & 1.000 & 1.000 \\
4 & 0.432 & 0.349 \\
5 & 0.622 & 0.621 \\
6 & 0.467 & 0.453 \\
7 & 0.495 & 0.716 \\
8 & 0.407 & 0.368 \\
9 & 0.637 & 0.566 \\
\hline
\end{tabular}


The Grey relation grade is calculated by using equation (8), which is the overall representative of all the responses. Thus, the multi-criteria optimization problem has been transformed into a single equivalent objective function optimization problem using the combination of Taguchi approach and Grey relational analysis. The higher is the value of the Grey relational grade represents that corresponding experiment result is closer the optimal [18]. The grey relation grade is shown in Table 8.

Table 8. Gray relation grade

\begin{tabular}{ccc}
\hline Specimen No. & Grey Relation Grade & Rank \\
\hline 1 & 0.333 & 9 \\
2 & 0.443 & 6 \\
3 & 1.000 & 1 \\
4 & 0.390 & 7 \\
5 & 0.622 & 2 \\
6 & 0.460 & 5 \\
7 & 0.605 & 3 \\
8 & 0.387 & 8 \\
9 & 0.601 & 4 \\
\hline
\end{tabular}

To determine the optimum turning parameters for cutting force and surface roughness, the average Grey relational grade for each turning process parameter level was calculated using the response table of Taguchi method. It was done by sorting the Grey relational grades corresponding to the levels of process parameter in each column of the orthogonal array and taking an average of those with the same level. For instance, in the first column of the orthogonal array, the No. 1, No. 2 and No. 3 were the experimental runs in which cutting speed parameter (S) was set at level 1. The associated values of the Grey relational grade of ' $S$ ' are those experimental runs' Grey relational grades. Therefore, their average is the average Grey relational grade for cutting speed (S):

S $($ level 1$)=(0.333+0.443+1.000) / 3=0.592$

Similarly, the average Grey relational grade of S at level 2 and 3 are calculated as follows.

$\mathrm{S}($ level2 $)=(0.390+0.622+0.460) / 3=0.490$

$\mathrm{S}($ Level 3$)=(0.605+0.387+0.601) / 3=0.531$

Using the same method, calculations was performed for all process parameters and the response table for the Grey relational grade is presented in Table 9 and also represented graphically in Fig. 2. From the Table 9, the difference between the maximum and the minimum value of the Grey relational grade of the turning process parameters is as follows: cutting speed (0.102), feed rate (0.245), depth of cut (0.349), lubricant type (0.090). By examining these values, the significance of each controllable factor on the performance characteristics can be determined. The most effective and controllable factor is the maximum of these values. Here, the maximum value among these values is 0.349 . This value indicates that the depth of cut is the strongest influence factor on the multi-performance characteristics compared to other turning parameters. 


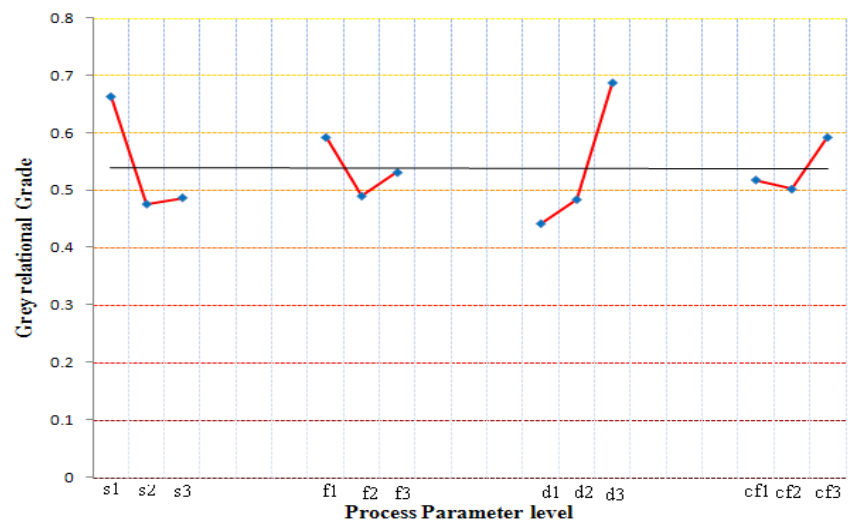

Fig. 2. Gray relational grade graph

Table 9. Response table for the Grey relational grade

\begin{tabular}{ccccc}
\hline Factors & \multicolumn{4}{c}{ Grey Relation grade } \\
& Level 1 & Level 2 & Level3 & Max-Min \\
\hline Speed & 0.592 & 0.490 & 0.531 & 0.102 \\
Feed & 0.442 & 0.484 & 0.687 & 0.245 \\
Depth of cut & 0.393 & 0.478 & 0.742 & 0.349 \\
Cutting Fluid & 0.518 & 0.502 & 0.592 & 0.090 \\
& & & \\
& \multicolumn{4}{c}{ Total mean Grey relational grade $=0.537$} \\
\hline
\end{tabular}

In the Grey relational grade graph, the dashed line represents the value of the total mean of the Grey relational grade. Basically, the larger the Grey relational grade, the better is the multiple-performance characteristics. Accordingly, the level has been selected that gave the largest average response. From the response Table 9 and Grey relational grade graph Fig.4, the best combination of the turning parameters for improved surface finish with lower cutting force is the set with S1 (cutting speed, 490), f3 (feed, 0.108), d3 (depth of cut, 1) and cf3 (cutting fluid type, straight cutting oil).

\subsection{ANOVA}

ANOVA is a statistical technique for determining the significance of the process parameters affecting the quality characteristics. In this present investigation, Pareto ANOVA technique [19] was employed, which determines the importance of each process parameter of the process. The Pareto ANOVA technique is a quick and easy method to analyse the results of the parametric design and also not required to conduct the F-test. This method finds the important parameters and also calculates the percentage of influence of each parameter on different responses [13].

From the $\mathrm{S} / \mathrm{N}$ ratios, the overall $\mathrm{S} / \mathrm{N}$ ratio is expressed as

$$
\overline{S / N}=\frac{1}{9} \sum_{1}^{9}(S / N)_{i}
$$


Where, $\overline{S / N}$ is the overall mean of $\mathrm{S} / \mathrm{N}$ ratio and $(S / N)$ is the $\mathrm{S} / \mathrm{N}$ ratio for $\mathrm{i}^{\text {th }}$ parameter

The sum of squares due to variation about overall mean is

$$
S S=\sum_{i=1}^{9}\left((S / N)_{i}-\overline{(S / N)}\right)^{2}
$$

Where, $S S$ is the sum of squares. For the $\mathrm{i}^{\text {th }}$ process parameter, the sum of squares due to variation about overall mean is

$$
S S_{i}=\sum_{j=1}^{3}\left((S / N)_{i j}-\overline{(S / N)}\right)^{2}
$$

Where, $S S_{i}$ is the sum of the square for $i^{\text {th }}$ parameter and $(S / N)_{i j}$ is the average $S / N$ ratio of $i^{\text {th }}$ parameter of $j^{\text {th }}$ level

$$
\% \text { Contribution }=\frac{S S_{i}}{S S} \times 100
$$

ANOVA test was conducted to determine the degree of importance of each parameter, namely, speed, feed depth of cut and cutting fluid for each response and results are presented in Table 10.

Table 10. Contribution of process parameters

\begin{tabular}{ccc}
\hline Process parameter & Sum of squares $\left(\mathrm{SS}_{\mathrm{i}}\right)$ & \% Contribution \\
\hline Speed & & 4.72 \\
Feed & 0.066622 & 31.02 \\
Depth of cut & 0.172598 & 60.10 \\
Cutting fluid & 0.116206 & 4.16 \\
\hline
\end{tabular}

The ANOVA results indicate that the depth of cut $(60.10 \%)$ is the major factor affecting cutting force and surface roughness of turning of EN 8 steel followed by feed (31.02\%), cutting speed (4.72\%), and cutting fluid $(4.16 \%)$.

\subsection{Regression Equations}

Regression analysis is used to develop the relationships between the process parameters and responses for predicting intermediate values within the range of the level. Nonlinear regression models are developed based on the experimental results to predict the cutting force and surface roughness. It is found that a second order polynomial curve fits the experimental values well. The correlations obtained between process parameters and outcomes are as follows.

Cutting force $(\mathrm{F})=-19.8071 \mathrm{~s}+7.34143 \mathrm{f}+9.66238 \mathrm{~d}+11.0233 \mathrm{cf}+5.99286(\mathrm{~s} \times \mathrm{f})+6.66714(\mathrm{~s} \times \mathrm{d})+7.01571$ (f×cf) $-1.25841 \quad R^{2}=99.27$ 
Surface roughness $(\mathrm{Ra})=2.96190 \mathrm{~s}+4.32429 \mathrm{f}-3.82286 \mathrm{~d}-0.650000 \mathrm{cf}-2.35143(\mathrm{~s} \times \mathrm{f})+1.29143(\mathrm{~s} \times \mathrm{d})+$ 1.18714 (f×cf) $-0.50412 \quad R^{2}=99.93$

\section{Conclusion}

The turning process parameters were optimized to yield better surface roughness at lower cutting forces. The optimal process parameters are $490 \mathrm{rpm}$ cutting speed, $0.108 \mathrm{~mm} / \mathrm{sec}$ feed, $1 \mathrm{~mm}$ depth of cut and straight cutting oil. The percentage of contribution of process parameters on responses was evaluated. It is noted that the depth of cut $(60.10 \%)$ is a significant factor affecting cutting force and surface roughness followed by feed $(31.02 \%)$, cutting speed $(4.72 \%)$ and cutting fluid (4.16\%) .

\section{References}

[1] Merchant, ME, Mechanics of the metal cutting process. Journal of Applied Physics, Vol. 16, 1945, pp.318-324.

[2] Finides, B, Aouici, H, Yallese, M A. Cutting forces and surface roughness in hard turning of hot work steel X38CrMoV5-1 using mixed ceramic, Journal Mechanical Vol.2(7), 2008, pp.73-78.

[3] Dilbag, S P, Venkateswarao R.,A surface roughness prediction model for hard turning process. International Journal Manufacturing Technology, Vol. 31, 2007, pp.1115-1124.

[4] Bouacha, K., Yallese, Ma., Mabrouki, T., and Rigak, JF. Statistical analysis of surface roughness and cutting forces using response surface methodology in hard turning of AISI 52100 bearing steel with CBN tool, International Journal of Refractory Metals and Hard Materials, Vol.28,2010, pp.349-361.

[5] Wang HY, Lan T S, parametric optization on multi objective presentation turning using Grey relational Analysis. Information Technology Journal, Vol.7(7), 2008, pp.1072-1076.

[6] Yahya Y, An experimental investigation on effect of cutting fluid in turning with coated carbides tool. Journal of Mechanical Engineering, Vol. 56, 2010, pp.1-7.

[7] Yazdani F, Hosseini SM, Barforuoshi T, A New Optimization Model for Distribution Siting and Sizing in Unbalanced Three-phase Networks for Loss and Cost Minimization. I.J. Engineering and Manufacturing,2014, pp.1-11.

[8] Wang J, Wang W, Wu S, A New Support Vector Machine Optimized by Simulated Annealing for Global Optimization. I.J. Engineering and Manufacturing,2012, pp. 8-14.

[9] Mahdavinejad, RA, Saeedy S, Investigation of the influence parameters of machining of AISO304 stainless steel. Sadhana, Vol.36,2011, pp.6, pp. 963-970.

[10] Allattin K, Ferhat Y, Application of Grey relational analysis in high-speed machining of hardend AISI D6 steel. Proc/Mech E Part c: Journal Mechanical Engineering Science,Vol. 227(7), 2012, pp.1566-1576.

[11] YinFong T, Fu-Chen, Multi-objective process optimization for turning of tool steels. International Journal of Machining and Machinability of Materials, Vol.1(1), 2006, pp.76-93.

[12] Phadke S M, Quality Engineering using robust design Englewood cliffs. National Journal Prantice Hall, 1989.

[13] Roy R., A Primer on the Taguchi Method. 1990, Van Nostrand Reinhold.

[14] Deng J L, Introduction to Grey system. The Journal of Grey System, Vol.1, 1989, pp.1-24.

[15] Vijaya K, Chincholkar A M., Effect of machining parameters on surface roughness and material removal rate in polymer pipes. Materials and Design, vol.31, 2010, pp.3590-3598.

[16] Wen, K L, The Grey system analysis and its application in gas breakdown. The International Journal of Computational Cognition, Vol.2, 2004, pp.21-44. 
[17] Asokan P, Kumar R R, Jeyapaul R., Santhi M , Development of multi-objective optimization models for electrochemical machining processes. International Journal of AdvancedManufacturingTechnology, Vol. 39, 2008, pp.55-63.

[18] Datta S , Bandyopadhyay A, Pal P K, Application of Taguchi philosophy for parametric optimization of bead geometry and HAZ width in submerged arc welding using mixture of fresh flux and fused slag. International Journal of Advanced ManufacturingTechnology,36,(2008), 689-698.

[19] Venkateswarlu G, Davidson M J., and Tagore G R. N, Influence of process parameters on the cup drawing of aluminum 7075 sheet. International Journal of Engineering Science Technology, Vol. 2, 2010, pp. 4049.

\section{Author(s) Profile}

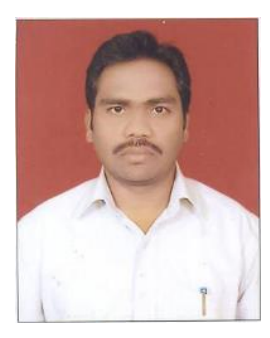

G. Sridhar is an Asst. Professor in Mechanical Engineering Department, Sree Chaitanya College of Engineering, Karimnagar. He got his M. Tech in Production Engineering from SV University, Tirupati. His research interests are machining, welding, casting etc.

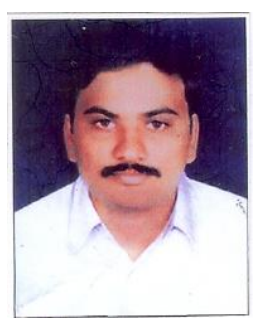

G. Venkateswarlu is a Professor in Department of Mechanical engineering, Sree Chaitanya College of Engineering, Karimnagar. He obtained his PhD from NIT Warangal and M. Tech in Manufacrurung from NIFFT. He is actively doing research in the fields of welding, forming and casting. He has more than 14 years experience in teaching. He has published more than 25 papers in International Journals.

How to cite this paper: G. Sridhar, G. Venkateswarlu,"Multi Objective Optimisation of Turning Process Parameters on EN 8 Steel using Grey Relational Analysis", IJEM, vol.4, no.4, pp.14-25, 2014.DOI: 10.5815/ijem.2014.04.02 